\title{
Convergent Evolution of C239S Mutation in Pythium spp. $\beta$-Tubulin Coincides with Inherent Insensitivity to Ethaboxam and Implications for Other Peronosporalean Oomycetes
}

\author{
Zachary A. Noel, ${ }^{1}$ Hyunkyu Sang, ${ }^{1,2}$ Mitchell G. Roth, ${ }^{1,3}$ and Martin I. Chilvers ${ }^{1,2,3, \dagger}$ \\ ${ }^{1}$ Department of Plant, Soil and Microbial Sciences, Michigan State University, East Lansing, Michigan \\ ${ }^{2}$ Program in Ecology, Evolutionary Biology and Behavior, Michigan State University, East Lansing, Michigan \\ ${ }^{3}$ Genetics Program, Michigan State University, East Lansing, Michigan \\ Accepted for publication 8 May 2019.
}

ABSTRACT

\begin{abstract}
Ethaboxam is a benzamide antioomycete chemical (oomicide) used in corn and soybean seed treatments. Benzamides are hypothesized to bind to $\beta$-tubulin, thus disrupting microtubule assembly. Recently, there have been reports of corn- and soybean-associated oomycetes that are insensitive to ethaboxam despite never having been exposed. Here, we investigate the evolutionary history and molecular mechanism of ethaboxam insensitivity. We tested the sensitivity of 194 isolates representing 83 species across four oomycete genera in the Peronosporalean lineage that were never exposed to ethaboxam. In all, $84 \%$ of isolates were sensitive to ethaboxam (effective concentration to reduce optical density at $600 \mathrm{~nm}$ by $50 \%$ when compared with the nonamended control $\left[\mathrm{EC}_{50}\right]<5 \mu \mathrm{g} \mathrm{ml}^{-1}$ ), whereas $16 \%$ were insensitive $\left(\mathrm{EC}_{50}>11 \mu \mathrm{g} \mathrm{ml}^{-1}\right)$. Of the insensitive isolates, two different transversion mutations were present in the 239th codon in $\beta$-tubulin within three monophyletic groups of Pythium spp. The transversion mutations lead to the same amino acid change from an ancestral cysteine to serine (C239S), which coincides with ethaboxam
\end{abstract}

insensitivity. In a treated soybean seed virulence assay, disease severity was not reduced on ethaboxam-treated seed for an isolate of Pythium aphanidermatum containing a S239 but was reduced for an isolate of $P$. irregulare containing a $\mathrm{C} 239$. We queried publicly available $\beta$-tubulin sequences from other oomycetes in the Peronosporalean lineage to search for C239S mutations from other species not represented in our collection. This search resulted in other taxa that were either homozygous or heterozygous for C239S, including all available species within the genus Peronospora. Evidence presented herein supports the hypothesis that the convergent evolution of $\mathrm{C} 239 \mathrm{~S}$ within Peronosporalean oomycetes occurred without selection from ethaboxam yet confers insensitivity. We propose several evolutionary hypotheses for the repeated evolution of the C239S mutation.

Keywords: C239S, convergent evolution, disease control and pest management, ethaboxam, genetics and resistance, mycology, oomycetes
Oomycetes are a diverse group of nonphotosynthetic osmotrophic eukaryotic organisms phylogenetically distinct from true fungi, with whom they were initially classified (Beakes et al. 2012, Raffaele and Kamoun 2012). The ability of oomycetes to infect plants has evolved independently multiple times in several lineages; however, oomycetes can be pathogens of animals, algae, fungi, and other oomycetes (Thines and Kamoun 2010). They play critical environmental roles by recycling nutrients and maintaining plant and animal diversity in natural ecosystems (Gilbert 2002). Oomycetes can be broken into the Saprolegnialean, Peronosporalean, and basal lineages (Beakes et al. 2012; Thines 2014). The Peronosporalean lineage contains the greatest number of plantpathogenic species (Thines 2014) and is perhaps most well known for containing species such as Phytophthora infestans, which was the causal organism of the Irish potato famine in the 1800s. Multiple management strategies utilizing resistant plant varieties, chemical

†Corresponding author: M. I. Chilvers; chilvers@msu.edu

Funding: This project was supported by Agriculture and Food Research Initiative competitive grant number 2011-68004-30104 from the United States Department of Agriculture National Institute of Food and Agriculture, Michigan Soybean Promotion Committee, United Soybean Board, North Central Soybean Research Program, and Valent U.S.A. LLC.

*The $\boldsymbol{e}$-Xtra logo stands for "electronic extra" and indicates that two supplementary figures and two supplementary tables are published online.

The author(s) declare no conflict of interest.

This article is in the public domain and not copyrightable. It may be freely reprinted with customary crediting of the source. The American Phytopathological Society, 2019. treatments, and cultural techniques are required to minimize disease in agricultural settings.

Although the use of plant resistance $(R)$ genes can be an effective strategy for disease management, they often protect against a single pathogen species or specific pathotype within that species. For example, there are many pathotypes of Phytophthora sojae, determined by their gene-for-gene relationship with various soybean varieties harboring specific $R$ genes (Whitham et al. 2016). $R$ genes can be overcome quickly, making chemical intervention a necessary part of an integrated management strategy (Fry 2008). Additional management strategies in corn and soybean production include tillage; however, soil conservation practices have advocated the adoption of minimum or no-till operations, which increases the amount of crop debris in fields. Also, growers are planting earlier to increase growing days and yield potential (Vossenkemper et al. 2015). As a result of these agricultural practices, seed may be exposed to prolonged adverse conditions as soils slowly warm and organic debris can act as an inoculum substrate for plant pathogens, including oomycetes (Larkin 2015). In North America, more than 80 oomycete species are associated with corn and soybean diseases (Broders et al. 2009; Rojas et al. 2017a,b; Zitnick-Anderson and Nelson 2015). Information regarding plant varieties with effective $R$ genes or partial resistance against all these species is mostly unknown (Rupe et al. 2011).

Consequently, antioomycete chemicals (appropriately named oomicides or oomyceticides) (Govers 2001; Lamberth et al. 2007) applied as seed treatments remain a vital management tool (Bradley 2008). A commonly applied oomicide is metalaxyl or its active stereoisomer, mefenoxam (Gisi and Sierotzki 2015). Resistance to metalaxyl or mefenoxam may be an issue because isolates with varying levels of sensitivity have been isolated from Ohio (Broders 
et al. 2007; Dorrance et al. 2004). However, the frequency of resistance in this agricultural production system is expected to be low because exposure is less frequent compared with other agricultural systems, where soil drenches or foliar applications are applied multiple times per growing season (Brent and Hollomon 1998; Gisi and Sierotzki 2015). Additionally, resistant genotypes of soilborne oomycetes may not spread as rapidly as foliar pathogens. However, interspecific differences in oomicide sensitivity can pose threats (Broders et al. 2007; Weiland et al. 2014).

The oomicide ethaboxam was registered for use on corn and soybeans in 2014 and, in 2017, an estimated 40\% (36 million acres) of corn seed in the United States was treated with ethaboxam (D. McDuffee, personal communication). Ethaboxam has shown efficacy against multiple oomycete isolates and species, including metalaxyl- or mefenoxam-resistant isolates (Chen and Van Vleet 2016; Kim et al. 1999, 2004). The efficacy of ethaboxam makes it a valuable tool for oomycete management in situations where multiple species can cause disease, or where metalaxyl or mefenoxam resistance is problematic. However, in preliminary in vitro and in vivo tests, Pythium aphanidermatum was not influenced by ethaboxam (Dorrance et al. 2012). Subsequent in vitro studies have shown that some other soybean- and corn-associated Pythium isolates belonging to multiple species were insensitive to ethaboxam but were isolated before the registration and use of ethaboxam (Matthiesen et al. 2016; Noel et al. 2019; Radmer et al. 2016). Due to reports of interspecific differences in ethaboxam sensitivity and its broad adoption by growers throughout the United States, it is essential to investigate the molecular and evolutionary mechanism of ethaboxam insensitivity so that appropriate recommendations for the use of ethaboxam are made.

Ethaboxam belongs to a group of fungicides called the benzamides, along with zoxamide and zarilamide, and their mode of action is through disruption of microtubule assembly (Young 2015). Microtubules are polymers of $\alpha$ - and $\beta$-tubulin, which are essential for mitotic separation of chromosomes during cell division and are significant constituents of the cytoskeleton. The importance of microtubules makes them targets for drug development for agricultural and clinical reasons (Jordan and Wilson 2004). Ethaboxam fragmented microtubules in Phytophthora infestans after $30 \mathrm{~min}$ of exposure at $0.01 \mu \mathrm{g} \mathrm{m} \mathrm{m}^{-1}$, which obstructed nuclear division and cytoskeletal structure (Uchida et al. 2005). Disruption of microtubule integrity aligns with the proposed mechanism of zoxamide and zarilamide (Young 2015). Young and Slawecki (2001) showed that zoxamide and zarilamide compete with each other for binding on $P$. capsici $\beta$-tubulin, demonstrating a common binding site. Zoxamide and structurally similar analogs have been shown to compete with the drug T138067 for binding on bovine $\beta$-tubulin between the residues 217 and 241 at the colchicine binding site (Uppuluri et al. 1993), or the interface of $\alpha$ - and $\beta$-tubulin heterodimers (Young et al. 2006). Binding at these residues is highly suggestive that zoxamide and zarilamide bind within the colchicine site on $\beta$-tubulin. T138067 has a highly specific covalent interaction to the cysteine residue at the 239th position (C239) in bovine $\beta$-tubulin (Shan et al. 1999). Young (2015) suggested that the zoxamide S-enantiomer and other benzamide fungicides interact with this residue as well. Genereplacement experiments with $P$. sojae confirmed that a nonsynonymous mutation, which changed the 239th amino acid from cysteine to serine (C239S), conferred resistance to zoxamide (Cai et al. 2016). Similar studies have not been performed with ethaboxam, and the molecular mechanism of ethaboxam insensitivity is currently unknown. However, its structural similarity with zoxamide and zarilamide and the proposed mode of action leads to the hypothesis that ethaboxam also interacts with the 239th residue of $\beta$-tubulin.

We hypothesize that interspecific differences in sensitivity are related to inherent differences in the $\beta$-tubulin protein sequence, not due to a selection from ethaboxam exposure. We also hypothesize that a change at the 239th residue of $\beta$-tubulin confers resistance to ethaboxam, as it does for other benzamide chemicals. To investigate these hypotheses we set the following objectives: (i) test ethaboxam sensitivity of 195 oomycete isolates representing 83 species and four genera collected from different geographic regions without previous exposure to ethaboxam, (ii) examine genetic and evolutionary mechanisms of ethaboxam insensitivity by characterizing the $\beta$-tubulin protein sequence, (iii) demonstrate the relevance of sensitivity differences between species in an ethaboxam-treated seed infection assay, and (iv) query available $\beta$-tubulin sequences for C239S mutations in other Peronosporalean oomycete species.

\section{MATERIALS AND METHODS}

Oomycete cultures. Oomycete cultures used in this study were isolated from soybean roots across the Midwestern United States by collaborators of an Oomycete Soybean Cooperative Agricultural Project in 2011 and 2012, before the registration and use of ethaboxam (Rojas et al. 2017a,b). Pythium folliculosum CBS 220.94 (Switzerland), P. ornacarpum CBS 112350 (Paul 1999) and $P$. radiosum CBS 217.94 (Paul 1992) (France), and $P$. selbyi CBS 129728 (Ellis et al. 2012) (Ohio) were isolated between 1992 and 2012, again before the registration and use of ethaboxam (Westerdijk Fungal Biodiversity Institute CBS-KNAW culture collection, Utrecht, The Netherlands). Saprolegnia sp. NTF5B-16 was cultured from Acipenser fulvescens eggs and used as an outgroup for phylogenetic analysis. $P$. deliense MBL39 was isolated in Uganda from Phaseolus vulgaris in 2013-14. In total, this study examined ethaboxam sensitivity of 194 isolates representing 83 oomycete species within the Peronosporalean lineage. Peronosporalean oomycetes included 67 Pythium, 8 Phytophthora, 7 Phytopythium, and 1 Pythiogeton spp. (Supplementary Table S1).

Fungicide sensitivity screening. Fungicide sensitivity screening was performed with a high-throughput fungicide phenotyping platform, as described by Noel et al. (2019). Briefly, technicalgrade ethaboxam was dissolved in $99.5 \%$ acetone. Isolates were tested in amended dilute V8 broth medium containing ethaboxam concentrations of $0,0.01,0.1,1,5$, and $20 \mu \mathrm{g} \mathrm{ml}^{-1}$ or $0,0.01,0.1,1,10$ and $100 \mu \mathrm{g} \mathrm{ml}^{-1}$. Medium amended with $0.0995 \%$ (vol/vol) acetone was used for the control. The isolates were allowed to grow for 24 to $48 \mathrm{~h}$ at $24^{\circ} \mathrm{C}$, with optical density at $600 \mathrm{~nm}\left(\mathrm{OD}_{600}\right)$ measurements taken at regular time intervals. The OD for each isolate was transformed to percent relative growth by dividing the mean OD of each ethaboxam concentration by the mean OD of growth with ethaboxam at $0 \mu \mathrm{g} \mathrm{ml}^{-1}$, multiplied by 100 , and the mean effective concentration to reduce $\mathrm{OD}_{600}$ by $50 \%$ when compared with the nonamended control $\left(\mathrm{EC}_{50}\right)$ was estimated for each isolate. Doseresponse analysis was carried out with the 'drc' package (Ritz and Streibig 2015) in Rv3.5.2 (R Core Team 2018). Percent relative growth was modeled against log-transformed fungicide doses using a four-parameter log-logistic model. The absolute $\mathrm{EC}_{50}$ was estimated by solving for the concentration where $50 \%$ inhibition took place (Noel et al. 2018).

DNA extraction. Five plugs of cultures growing on corn meal agar (CMA) amended with PARPB (pentachloronitrobenzene at $50 \mathrm{mg} \mathrm{liter}{ }^{-1}$, ampicillin at $250 \mathrm{mg}$ liter $^{-1}$, rifampicin at $10 \mathrm{mg}$ liter ${ }^{-1}$, pimaricin at $5 \mathrm{mg} \mathrm{liter}{ }^{-1}$, and benomyl at $10 \mathrm{mg} \mathrm{liter}^{-1}$ ) (Jeffers 1986) were grown in $10 \% \mathrm{~V} 8$ broth containing $0.5 \mathrm{~g}$ of $\mathrm{CaCO}_{3}$. Mycelia were harvested and lyophilized overnight. Approximately 25 to $30 \mathrm{mg}$ of lyophilized mycelium was ground with approximately $150 \mu \mathrm{l}$ of lysing matrix A (MP Biomedicals, Houston, TX, U.S.A.) and a 4-mm-diameter steel ball (SPEX SamplePrep, Metuchen, NJ, U.S.A.) using a FastPrep FP120 (Thermo Fisher Scientific, Waltham, MA, U.S.A.), and genomic DNA (gDNA) was extracted using the DNeasy Plant Mini Kit (Qiagen Sciences Inc., Germantown, MA, U.S.A.) or OMEGA Mag-Bind Plant DNA Plus kit (Omega Bio-Tek, Norcross, GA, U.S.A.) by following the manufacturer's instructions. 
DNA amplification, $\beta$-tubulin sequencing, and identification of C239S mutations. Preliminary studies indicated that $\beta$-tubulin sequences from oomycete genomes matched the length and reading frame of Pythium ultimum cDNA (AF218256) from $\mathrm{Mu}$ et al. (1999). Therefore, gDNA was used instead of cDNA for most isolates because it was determined that introns were not present. Full-length $\beta$-tubulin sequences $(1,341 \mathrm{bp})$ from an isolate of $P$. aphanidermatum (NDSO_L_8-6), P. torulosum (MISO_8-29.1), $P$. rostratifingens (C-NESO2_6-5), $P$. ultimum var. ultimum (KSSO_5-45), P. irregulare (ILSO_1-31), P. sylvaticum (NESO_ 2-13), and Phytophthora sojae (IASO_3-41.17) were amplifiefrom gDNA or cDNA libraries with custom primers and cloned into plasmid pYES2 (Invitrogen, Carlsbad, CA, U.S.A.) for Sangersequencing (Supplementary Table S2). Additionally, a smaller internal $(1,050 \mathrm{bp})$ region of the $\beta$-tubulin gene was amplified and sequenced from 48 isolates representing 37 oomycete species using primers BT6 (5'-CAAGAAAGCCTTACGACGGA-3') (Villa et al. 2006) and Oom-Btub-up-415 (5'-CGCATCAACGTGTACTA CAA-3') (Bilodeau et al. 2007). Sequencing with BT5 (5'GTATCATGTGCACGTACTCGG-3') (Villa et al. 2006) was also used for some isolates. All polymerase chain reactions (PCR) consisted of $1 \times$ Phusion HF buffer containing $1.5 \mathrm{mM} \mathrm{MgCl}$, $0.2 \mathrm{mM} \mathrm{dNTP}, 0.5 \mathrm{U}$ of Phusion polymerase, $0.2 \mu \mathrm{M}$ forward and reverse primers, and 1 to $10 \mathrm{ng}$ of gDNA. Thermal cycling conditions were as follows: $98^{\circ} \mathrm{C}$ for $5 \mathrm{~min}$; followed by 35 cycles of $98^{\circ} \mathrm{C}$ for $1 \mathrm{~min}, 60^{\circ} \mathrm{C}$ for $45 \mathrm{~s}$, and $72^{\circ} \mathrm{C}$ for $1.5 \mathrm{~min}$; followed by a final extension at $72^{\circ} \mathrm{C}$ for $7 \mathrm{~min}$. Successful amplification was checked on a $1.5 \%$ agarose gel and the remaining PCR product was purified by adding $5 \mu \mathrm{l}$ containing $3 \mathrm{U}$ of exonuclease I and $0.5 \mathrm{U}$ of shrimp alkaline phosphatase (Thermo Scientific), and incubating at $37^{\circ} \mathrm{C}$ for $45 \mathrm{~min}$ followed by enzyme inactivation at $85^{\circ} \mathrm{C}$ for $10 \mathrm{~min}$. $\beta$-Tubulin amplicons were Sanger-sequenced via Macrogen USA (Rockville, MD, U.S.A.) or at the Michigan State University Genomics core. Raw sequence files were trimmed and assembled with Codon Code Aligner v4.2.7 (Centerville, MA, U.S.A.), and consensus sequences were generated for downstream analysis. $\beta$-Tubulin consensus sequences were then aligned to full-length coding sequences from Pythium ultimum var. ultimum (AF218256) (Mu et al. 1999) using MUSCLE (Edgar 2004), and sequences were translated in frame to examine nonsynonymous changes to $\beta$-tubulin.

$\beta$-Tubulin phylogenetics and ancestral state reconstruction. $\beta$-Tubulin sequences were aligned with MUSCLE and terminal gaps were treated as missing data, using Saprolegnia sp. (NTF5B16) $\beta$-tubulin as an outgroup. In total, the alignment consisted of 858 characters corresponding to amino acids 92 to 377 of $\beta$-tubulin. The Markov Chain Monte Carlo (MCMC) method as implemented in MrBayes (Ronquist et al. 2012) was run with 5,000,000 generations, $25 \%$ burn-in, and eight chains with a GTR $+\mathrm{I}+\Gamma$ model, as estimated by MrModelTest2 implemented in PAUP*4.0a161 (Swofford 2002). First, second, and third codon positions were treated as separate partitions. Tracer v1.6.0 was used to assess convergence and stationarity in the MCMC runs. Ancestral states were estimated in a separate analysis by constraining selected nodes and setting the 'ancestates' option to 'yes'. Constraints were set to only include descendants of a node. The same MrBayes settings as above were used, except with only 1,000,000 generations, four chains, and trees sampled every 500 generations. The ancestral nucleotides were reported as the posterior probability of each nucleotide in the alignment at each constrained node. Ancestral amino acids were translated from the most probable nucleotide at each codon position for each selected node.

Treated seed virulence assay. Isolates containing either C239 or S239 were tested for their ability to cause disease on ethaboxam treated seed. The virulence of $P$. aphanidermatum (isolate NDSO_ L_8-6, genotype C239) and P. irregulare (isolate ILSO_1-31, genotype S239) was tested using a modified seed rot assay (Broders et al. 2007; Rojas et al. 2017a). The fungicide fludioxonil does not have activity on oomycetes (http://www.cdms.net/ldat/ ldB6U001.pdf) and was included as a base treatment to reduce the competition from seedborne fungi. All soybean seed (AG2232) (Asgrow Seed Co., Monsanto, St. Louis, MO, U.S.A.) were treated with fludioxonil and fludioxonil with or without ethaboxam. Fludioxonil and ethaboxam were applied to soybean seed at commercial rates of 0.0038 and $0.012 \mathrm{mg} \mathrm{seed}^{-1}$, respectively. Oomycete isolates were grown on CMA+PARPB for 3 to 5 days; then, a 3.4-mm plug was transferred from the edge of an actively growing colony to the center of water agar plates $\left(20 \mathrm{~g} \mathrm{agar} \mathrm{liter}^{-1}\right)$ containing ampicillin (250 $\left.\mathrm{mg} \mathrm{liter}^{-1}\right)$ and benomyl $\left(5 \mathrm{mg} \mathrm{liter}^{-1}\right)$. Ampicillin and benomyl are both used commonly in oomycete isolation medium (Jeffers 1986) and were amended into assay plates to further reduce competition from bacterial and fungal growth.

Each isolate was allowed to grow for 2 days; then, 5 seeds were placed at the edge of each actively growing culture. Seed placed on noninoculated plates served as a negative controls. Plates were incubated for 7 days at $20^{\circ} \mathrm{C}$ before rating disease severity. Disease severity was rated as follows: $0=$ germinated healthy seed; $1=$ germinated with little discoloration; $2=$ germinated, lesions present but not coalesced; 3 = germinated with coalesced lesions; and $4=$ no germination and seed completely colonized (Broders et al. 2007; Rojas et al. 2017a) (Supplementary Fig. S1). Disease severity scores were converted to a percent disease severity referred to as the disease severity index (Broders et al. 2007; Rojas et al. 2017a). Each isolate was tested twice and the mean percent disease severity index was used as the response variable in a linear mixed model that treated isolate, seed treatment chemical, and the interaction terms as fixed effects, with biological replicate as a random effect.

Query of other oomycetes for C239S mutations. Pythium spp. $\beta$-tubulin sequences published by Hyde et al. (2014) were downloaded from the NCBI, and 101 Phytophthora spp. $\beta$-tubulin sequences available from the Phytophthora Database (http:// www.PhytophthoraDB.org) and other sequences from curated sources were downloaded from NCBI. Including sequences from this study, in total, $400 \beta$-tubulin sequences were analyzed. These sequences were aligned to full-length $\beta$-tubulin sequences using MAFFT v7.388 with the FF-NS-1 algorithm (Katoh and Standley 2013). An approximate maximum-likelihood phylogeny was generated using FastTree v2.1.10 with the GTR model (Price et al. 2010). The phylogeny was visualized in iTOL (https:// itol.embl.de) as a cladogram (Letunic and Bork 2016).

Data availability. All data, $R$ code, sequence alignments, and phylogenic tree files associated with this manuscript were deposited on GitHub (https://github.com/noelzach/C239SPeronosporaleanEvolution), and $\beta$-tubulin sequences were deposited in GenBank under the accession numbers MK752959 to MK753004.

\section{RESULTS}

Ethaboxam sensitivity of 83 oomycete species. Two categories describe the distribution of $\mathrm{EC}_{50}$ values for 195 isolates representing 83 species challenged with ethaboxam: isolates with $\mathrm{EC}_{50}<5 \mu \mathrm{g} \mathrm{ml}{ }^{-1}$ (sensitive) and those with $\mathrm{EC}_{50}>11 \mu \mathrm{g} \mathrm{ml}^{-1}$ (insensitive) (Fig. 1). Over three-quarters (84\%) of isolates representing 67 species had an $\mathrm{EC}_{50}$ for ethaboxam of $<5 \mu \mathrm{g} \mathrm{ml}^{-1}$ and are hereafter referred to as the sensitive (S) group. Isolates with an $\mathrm{EC}_{50}>11 \mu \mathrm{g} \mathrm{ml}^{-1}$ were broken into three groups based on previously established phylogenetic clades (LéVesque and De Cock 2004), hereafter referred to as insensitive 1, 2, and 3 (I1, I2, and I3). I1 consisted of three isolates belonging to two species: $P$. aphanidermatum and $P$. deliense. These two species are sister species within the previously established Pythium clade A (LéVesque and De Cock 2004). I2 consisted of six isolates belonging to the four species $P$. torulosum, Pythium aff. torulosum, $P$. folliculosum, and $P$. catenulatum, which are all part of previously established Pythium clade B (LéVesque and De Cock 2004). I3 consisted of 22 isolates belonging to 10 species-P. carolinianum, 
$P$. ornacarpum, $P$. radiosum, $P$. acrogynum, $P$. hypogynum, Pythium aff. hypogynum, $P$. longisporangium, $P$. selbyi, $P$. logandrum, and $P$. rostratifingens - which all belong to previously established Pythium clade E (LéVesque and De Cock 2004). All isolates in groups I1 and $\mathrm{I} 3$ had $\mathrm{EC}_{50}$ for ethaboxam of $>20 \mu \mathrm{g} \mathrm{ml}^{-1}$. Isolates within group $\mathrm{I} 2$ had $\mathrm{EC}_{50}$ for ethaboxam ranging from 11.18 to $>20 \mu \mathrm{g} \mathrm{ml}^{-1}$.

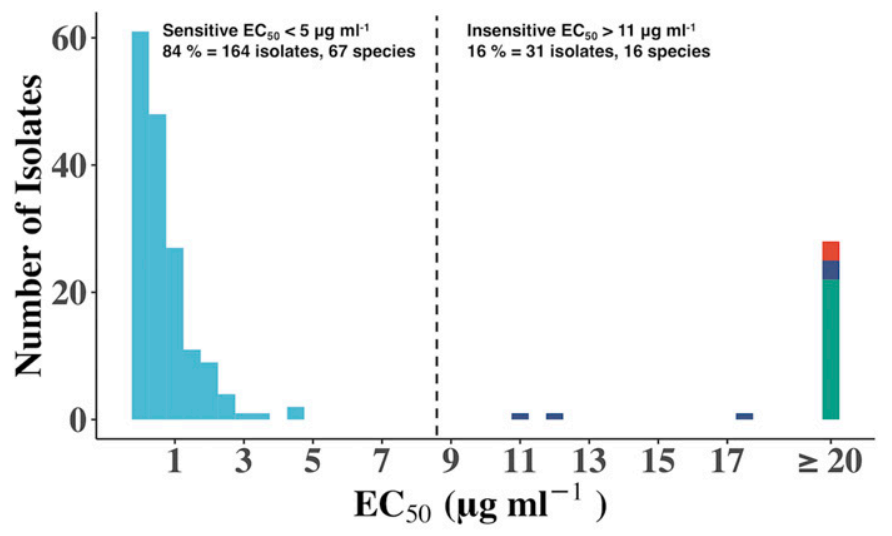

Insensitive 1 Insensitive $2 \quad$ Insensitive $3 \quad$ Sensitive

Fig. 1. Effective concentration to reduce optical density at $600 \mathrm{~nm}$ by $50 \%$ when compared with the nonamended control $\left(\mathrm{EC}_{50}\right)$ distribution of 195 isolates representing 83 oomycete species. Isolates were separated into sensitive and insensitive groups. The insensitive group was further separated into three groups based on previously established phylogenetic clades (LéVesque and De Cock 2004). Insensitive 1, 2, and 3 (I1, I2, or I3) group isolates all belonged to species within Pythium clades A, B, and E, respectively. Shading of bars represents sensitivity groups.
C239S mutation associated with insensitive isolates. To examine whether specific $\beta$-tubulin mutations were associated with ethaboxam sensitivity, full-length $\beta$-tubulin genes from one representative isolate of group I1 (P. aphanidermatum NDSO_L_ 8-6), group I2 (P. torulosum MISO_8-29.1), and group I3 (P. rostratifingens C-NESO2_6-5) along with four taxa from the $\mathrm{S}$ group were cloned and sequenced. The isolates used to represent the S group was an isolate of $P$. sylvaticum (NESO_2-13), P. ultimum var. ultimum (KSSO_5-45), P. irregulare (ILSO_1-31), and Phytophthora sojae (IASO_3-41.17). Five nonsynonymous mutations were present among all isolates at positions 42, 81, 239, 268, 365 , and 368 (Fig. 2). However, the only mutation common to all insensitive isolates used in this study was cysteine to serine substitution at position 239 (C239S). Mutations at positions 81 (F81Y) and 368 (V368I) were present in the S and I3 group and, therefore, were unlikely to contribute to ethaboxam insensitivity. Mutations at positions 42, 268, and 365 were in some insensitive isolates but not all. Pythium rostratifingens (group I3) contained a methionine at position 42 instead of a leucine (M42L). P. aphanidermatum (group I1) had a valine at position 268 instead of isoleucine $(\mathrm{I} 268 \mathrm{~V})$ and alanine at position 365 instead of thiamine (T365A). Differences in the amino acid sequences suggest that mutations in the $\beta$-tubulin protein structure between species could contribute to ethaboxam insensitivity; however, the C239S likely has a significant contribution because it was common to all insensitive taxa and was not present in any sensitive taxa (Fig. 2).

Evolution of ethaboxam insensitivity. Because each representative of groups I1, I2, and I3 contained C239S whereas the sensitive isolates did not, partial $\beta$-tubulin genes were sequenced to determine whether other isolates and species from groups I1, I2, and I3 also contained C239S. P. folliculosum CBS 220.94 and $P$. radiosum CBS 217.94 did not have publicly available


Py. ultimum var. ultimum (S) VRAG Pं FGQ FRPDN


Phytophthora sojae (S) VRAGP Y GQ GRPDNFVFGQTGAGNNWAKGHYTEGAEL I D S VLDVVRKEAESCDCLQGFQITHSLGGGTGSGMGTL Py. aphanidermatum (I1) VRAGP

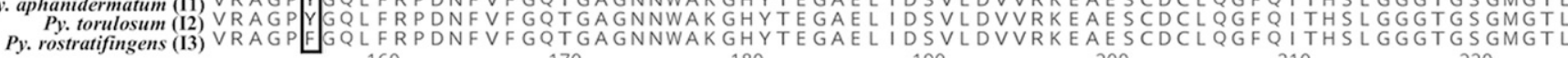

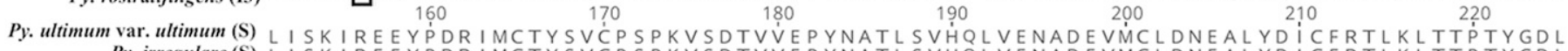
$170 \quad 180$ 190 210 220 Py. irregulare (S) L I SK IREEYPDR I MCTYSVCPSPKVSDTVVEPYNATLSVHQLVENADEVMCLDNEALYDICFRTLKLTTPTYGDL Py. sylvaticum (S) L ISK IREEYPDR IMCTYSVCPSPKVSDTVVEPYNATLSVHQLVENADEVMCLDNEALYDICFRTLKLTTPTYGDL Phytophthora sojae (S) L I SK IREEYPDR I MCTYS VCPSPKVSDTVVEPYNATLSVHQLVENADEVMCLDNEALYDICFRTLKLTTPTYGDL




230 $270 \quad 280 \quad 300$




Py: sylvaticum (S) NHLVCAAMSGITTCLRFPGQLNSDLRKLAVNLIPFPRLHFFMIGFAPLTSRGSQQYRALTVPELTQQQFDAKNMM Phytophthora sojae (S) NHL VCAAMSG I TTCLRFPGQLNSDLRKLAVNL I PFPRLHFFMIGFAPLTSRGSQQYRALTVPELTQQQFDAKNMM P. aphanidermatum (I1) NHLVCAAMS G T T S SLRFPGQLNSDLRKLAVNL IPFPRLHFFMVGFAPLTSRGSQQYRALTVPE L TQQQRDAKNMM

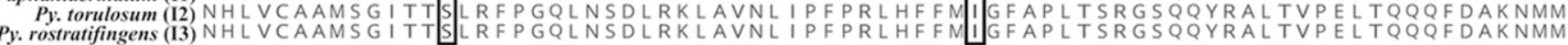
310 320 330 340 $35 \underline{0}$ $36 \underset{1}{3}$ 370



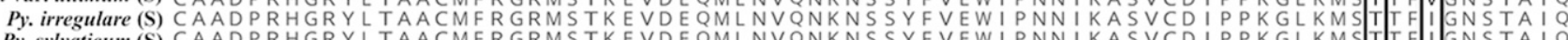

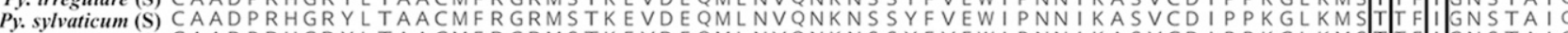
Phytophthora sojae (S) CAADPRHGRYLTAACMFR GRMSTKEVDEQMLNVQNKNSSYFVEWIPNN I KASVCDIPPKGLKMSTTF GNSTA I C Py. aphanidermatum (I1) C A ADPRHGRYLTAACMFRGRMSTKEVDEQMLNVQNKNSSYFVEWIPNNIKASVCDIPPKGLKMSATFIGNSTAIQ Py. torulosum (I2) CAADPRHGRYLTAACMFRGRMSTKEVDEQMLNVQNKNSSYFVEWIPNNIKASVCDIPPKGLKMSTTF I GNSTA I Q

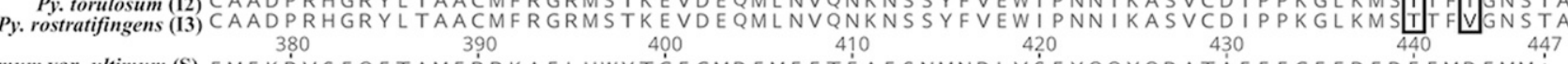
400 447

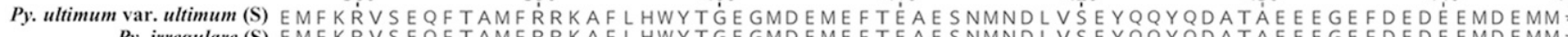
Py. irregulare (S) EMFKRVSEQFTAMFRRKAFLHWYTGEGMDEMEFTEAESNMNDLVSEYQQYQDATAEEEGEFDEDEEMDEMM* Py. sylvaticum (S) EMF KRVSEQFTAMFRRKAF L HWYTGE GMDEMEFTEAESNMNDLVSEYQQYQDATAEEEGEFDEDEEMDEMM*



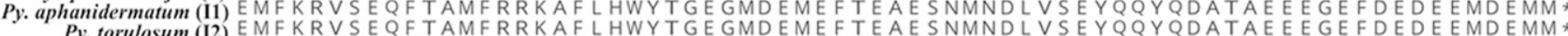
Py. rostratifingens (13) EMF KRVSEQFTAMFRR KAF L HWYTGE GMDEMEFTEAESNMNDLVSEYQQYQDATAEEEGEFDEDEEMDEMM*




Only taxa resistant to ethaboxam contained a serine at position 239 , whereas sensitive taxa had a cysteine. 
$\beta$-tubulin sequences, and partial sequences were generated in this study. A Bayesian phylogenetic framework revealed the evolutionary history and ancestral sequences of Pythium $\beta$-tubulin while also considering ethaboxam sensitivity (Fig. 3). The phylogeny had strong support (posterior probability $>70 \%$ ) corresponding to isolates within groups I1, I2, and I3. All isolates within groups I1, I2, and I3 were monophyletic, contained C239S mutations, and were significantly less sensitive to ethaboxam than isolates with a cysteine at residue 239. Ancestral sequence reconstruction of $\beta$-tubulin indicated that the plesiomorphic codon corresponding to position 239 in Pythium spp. translated to cysteine. However, the ancestral codons for groups I1, I2, and I3 translated to serine. The nucleotide mutation that resulted in a C239S substitution in isolates within group I3 was different than in groups I1 and I2. The most recent common ancestor of group I1 or I2 likely experienced a T to A transversion mutation at the first position of codon 239, while the most recent common ancestor of group I3 likely experienced a G to $\mathrm{C}$ transversion mutation at the second position of codon 239. Both nucleotide changes result in a nonsynonymous cysteine to serine mutation, suggesting that this mutation evolved at least three times via a convergent evolutionary mechanism despite never being exposed to ethaboxam.

Treated seed virulence assay. An isolate containing C239 (P. irregulare ILSO_1-31) displayed a 34.84\% reduction in disease severity on ethaboxam-treated seed relative to seed lacking ethaboxam $(P<0.001)$ (Fig. 4). In contrast, an isolate containing S239 (P. aphanidermatum NDSO_L_8-6) did not show a significant difference in disease severity in the presence of ethaboxam, with a mean percent disease severity index of $45.00 \pm 2.58$ without ethaboxam and $47.50 \pm 5.44$ with ethaboxam $(P=0.69)$ (Fig. 4).

C239S mutations present in other Peronosporalean oomycete taxa. Multiple independent mutations resulting in C239S substitutions in Pythium spp. (Fig. 3) warranted further investigation into $\beta$-tubulin sequences of other Peronosporalean oomycetes. In total, $400 \beta$-tubulin DNA sequences representing 15 genera revealed additional C239S substitutions in Peronosporalean oomycetes, including different isolates of the same species examined in this study, validating the present findings (Fig. 5;

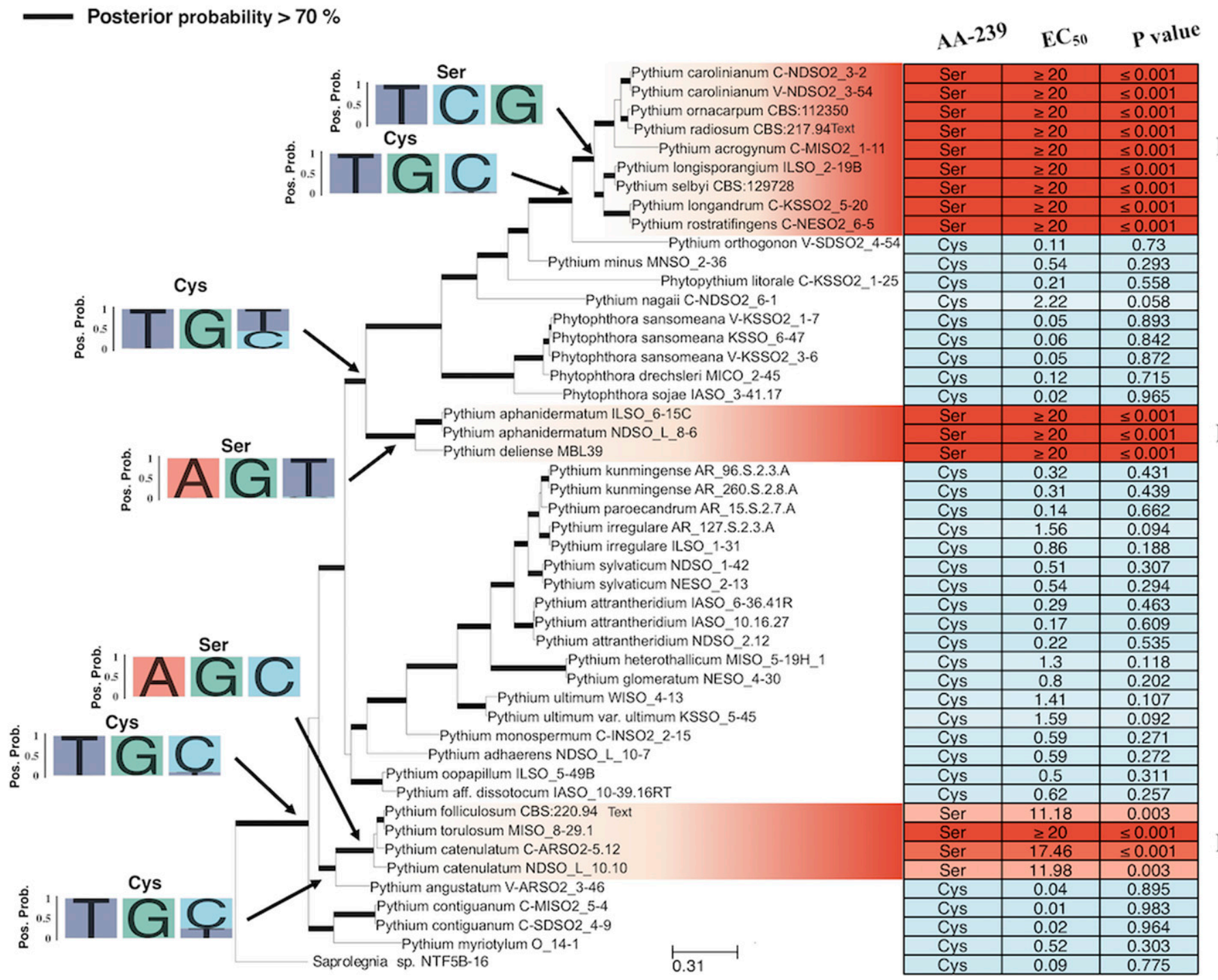

Fig. 3. Evolution of $\beta$-tubulin of 46 oomycete taxa and corresponding sensitivity to ethaboxam (effective concentration to reduce optical density at $600 \mathrm{~nm}$ by $50 \%$ when compared with the nonamended control $\left[\mathrm{EC}_{50}\right]$ ). The phylogeny was generated by the consensus of trees sampled in a Bayesian Markov Chain Monte Carlo analysis with a GTR+I+G model and first, second, and third codon positions treated as separate partitions. Thick branches indicate posterior probability $>70 \%$. Genotype indicates the amino acid at position 239 in $\beta$-tubulin coding sequence of extant taxa. The $P$ value column represents the significance of EC $_{50}$ values relative to the $\mathrm{EC}_{50}$ distribution of isolates containing a cysteine at position 239, in a one-sided $\mathrm{Z}$ test. Ancestral nucleotide sequences were reconstructed at selected nodes, and results were presented as the posterior probability of each nucleotide in $\beta$-tubulin genes. The posterior probability of nucleotides corresponding to codon 239 and translated amino acid are presented at each selected ancestral node. 
Supplementary Fig. S2). In addition, P. iwiami DAOM BR242034 contained a C239S substitution, and close relatives $P$. okanoganense CBS 315.81 and Pythium sp. rooibos 2 STE-U7550 were heterozygous for this locus (i.e., contained both C239 and S239). Furthermore, all sequences belonging to the genus Peronospora contained C239S, which indicates that the $\mathrm{C} 239 \mathrm{~S}$ has evolved many times independently within Peronosporalean oomycetes and also supports a convergent evolutionary mechanism.

\section{DISCUSSION}

In this study, the inherent sensitivity to ethaboxam of 194 Peronosporalean oomycete isolates representing 83 species and four genera was tested to examine the genetic and evolutionary mechanism of ethaboxam insensitivity. Multiple amino acid changes were present in insensitive Pythium isolates but the only common mutation to all insensitive isolates was a serine at position 239 instead of a cysteine. We further examined the evolutionary history of C239S mutations, which revealed for the first time that C239S mutations observed in extant Pythium spp. evolved independently from three ancestral taxa before ethaboxam was in use. Furthermore, we demonstrated that a pathogenic isolate containing the C239S mutation was able to infect soybean seed treated with ethaboxam at commercial rates, demonstrating the practical relevance of this mutation. To our knowledge, this is the first report of $\mathrm{C} 239 \mathrm{~S}$ mutation coinciding with ethaboxam resistance, and first exploration of $\beta$-tubulin sequences across the Peronosporalean oomycetes, which revealed that C239S mutations exist in other Peronosporalean oomycetes. The C239S mutation in these lineages may indicate that ethaboxam is not efficacious to these species; however, this hypothesis will need to be tested in future studies.

Three lines of evidence support our original hypothesis that repeated evolution of the $\mathrm{C} 239 \mathrm{~S}$ mutation was convergent and not due to a selection from ethaboxam exposure. First, isolates used in this study were collected from hosts rarely rotated with crops where other antioomycete benzamide chemicals such as zoxamide were used. Zoxamide is used in the products Gavel 75DF and Zing! (Gowen U.S.A., Yuma, AZ, U.S.A.), neither of which are registered for use on soybean or corn, which is where $95.8 \%$ of the cultures used in this study were isolated. Second, isolates containing C239S were collected from a vast geographic region. For example, the P. deliense MBL39 isolate (group I1) was isolated from dry bean in Uganda. P. folliculosum CBS 220.94 (group I2) was isolated from soil in Switzerland. P. ornacarpum CBS 112350 and P. radiosum



Fig. 4. Mean disease severity index of one insensitive isolate (Pythium aphanidermatum NDSO_L_8-6, genotype S239) and one sensitive (C239) isolate (P. irregulare ILSO_1-31, genotype C239) on soybean seed (AG2332) treated with either the control containing fludioxonil (F) or fludioxonil plus ethaboxam $(F+E)$.
CBS 217.94 (group I3) were isolated from soil in France. The remaining cultures were isolated from across the Midwestern United States. The probability that zoxamide or another benzamide was used over an extensive geographic region and consequently selected for C239S mutations in isolates used in this study is highly unlikely. Third, the reconstruction of ancestral $\beta$-tubulin genes suggested that the ancestral residue at position 239 in Pythium spp. was cysteine, which mutated to a serine in ancestors of groups I1, I2, and I3 (Fig. 3). These changes likely occurred well before the use of agricultural oomicides. Therefore, the prevalence of the C239S substitution could be a result of an unknown selection pressure or the result of genetic drift.

If C239S mutations are the result of selection, we hypothesize that the accumulation of C239S mutations in some species may be the result of defense against antibiosis, microtubule integrity, or assembly dynamics. For example, many naturally derived microtubuleinhibiting compounds such as colchicine, vincristine, vinblastine, nocodazole, and paclitaxel have been discovered from plants as secondary metabolites (Borisy and Taylor 1967, Lu et al. 2012). Other compounds produced by bacteria such as rhizoxin bind to $\beta$-tubulin and act in a mechanism of antibiosis or virulence (Loper et al. 2008; Partida-Martinez and Hertweck 2005; Schmitt et al. 2008). Therefore, it is reasonable to speculate that the $\mathrm{C} 239 \mathrm{~S}$ substitution in oomycete $\beta$-tubulin enables some species to colonize different environments. This hypothesis will have to be explored further.

C239S mutations may also provide structural microtubule integrity or improved microtubule assembly kinetics at different temperatures. For example, mutations in $\beta$-tubulin isotypes of Euplotes focardii, a psychrophilic protozoan, have been associated with cold adaptation by allowing differential flexibility in microtubules at cold temperatures (Chiappori et al. 2012). Matthiesen et al. (2016) observed that $P$. torulosum isolates (group I2) were less sensitive to ethaboxam at cooler temperatures. The association of point mutations in $\beta$-tubulin and ethaboxam sensitivity at different temperatures should be studied further.

Additionally, studying the evolution of this amino acid change in a broader evolutionary context by considering closely related organisms may provide additional insight regarding evolutionary mechanisms. For example, members of the Saprolegnialean lineage such as Aphanomyces cochlioides, A. euteiches, and Apodachyla brachynema contain a C239. Outside of the phylum Oomycota, the diatom Thalassiosira weissflogii contains a C239, whereas the brown algae Ectocarpus variabilis contains S239. Investigating these species was beyond the scope of the current study but could be of interest in future studies.

The results of the treated seed virulence assay provide management implications because they demonstrated that P. aphanidermatum (NDSO_L_8-6) was capable of causing disease on ethaboxam-treated seed. Because $P$. aphanidermatum inherently contains C239S, ethaboxam may not be efficacious when this species is the primary pathogen. For example, ethaboxam may not be efficacious as an alternative to mefenoxam in floriculture where mefenoxam-resistant $P$. aphanidermatum isolates can be problematic (Del Castillo Múnera and Hausbeck 2016; Lookabaugh et al. 2015; Moorman and Kim 2004). The results of the treated-seed virulence assay align with observations of Dorrance et al. (2012), who noted that ethaboxam did not reduce disease severity for $P$. aphanidermatum. Additionally, Rojas et al. (2017a) demonstrated that some species within group I3 (P. logandrum, P. longisporangium, and $P$. hypogynum) were not pathogenic toward seed but significantly reduced root area of soybean seedlings. Likewise, Pythium aff. torulosum (group I2) significantly reduced root area, root length, and root weight of soybean seedlings but was nonpathogenic to seed (Rojas et al. 2017a). Consequently, the efficacy of ethaboxam on oomycete species nonvirulent on seed but virulent on roots should be investigated in future studies.

Although the majority of isolates used in this study were Pythium isolated from soybean, we identified other Peronosporalean 
oomycetes with C239S mutations from public data repositories, and it will be necessary for future studies to evaluate ethaboxam sensitivity in isolates of these species. For example, all Peronospora sequences sampled contained a C239S mutation. In field trials, ethaboxam significantly reduced disease severity of Peronospora belbahrii and $P$. parasitica compared with the nontreated control but disease was significantly more severe on ethaboxam-treated plants compared with other commercial products (Raid et al. $2013 \mathrm{a}$, b). Therefore, it is currently unknown whether C239S mutations in Peronospora confer insensitivity to ethaboxam as observed for oomycete species in this study. Among other Pythium sequences from public repositories, three isolates (Pythium okanoganense CBS 315.81, Pythium sp. rooibos 2 STE-U7550, and $P$. nagii CBS 77.96) were heterozygous. The $P$. nagii isolate $(\mathrm{C}-$ NDSO2_6-1) from this study was homozygous for cysteine at position 239 and was sensitive to ethaboxam with a mean $\mathrm{EC}_{50}=$ 2.22. All of these species are closely related according to multigene phylogenies (Hyde et al. 2014). Therefore, it appears that heterozygosity may be common for some isolates of these species. It is unknown what phenotype heterozygous isolates would exhibit in the presence of ethaboxam but we speculate that they would display reduced sensitivity to ethaboxam because the S239 $\beta$-tubulin allele



Fig. 5. Approximate maximum-likelihood cladogram showing evolution of $\beta$-tubulin genes from 400 Peronosporalean oomycete taxa representing 14 genera. All sequences were from public repositories, except taxa sequenced in this study. Pythium sequences from Hyde et al. (2014) and Phytophthora sequences from PhytophthoraDB (http://www.PhytophthoraDB.org) were used. Numbers in parentheses next to taxa names represent the number of taxa within the collapsed node. Branches indicate where a C239S mutation occurred and black dashed lines indicate the sequence was heterozygous (i.e., cysteine or serine at position 239). The cladogram was generated using FastTree v1.2.10 with a GTR model. Numbers on branches indicate local support values $>0.7$. The cladogram was rooted with Saprolegnia $\beta$-tubulin sequences. 
would be expressed and incorporated into microtubules, which would compensate for the sensitive C239 allele.

The results of this study are highly suggestive that C239S is involved in ethaboxam insensitivity; however, other mechanisms are also possible. Insensitivity to antimicrobial compounds can be linked to overexpression of the target protein, expression of efflux mechanisms, or detoxification (Ma and Michailides 2005). These mechanisms could be present in other isolates, and it is essential to continue to monitor for ethaboxam insensitivity. Nonetheless, ethaboxam can be a valuable tool for oomycete management; however, special attention to the oomycete species present should be considered for appropriate use of ethaboxam.

\section{ACKNOWLEDGMENTS}

We thank the Oomycete Soybean Cooperative Agricultural Project extension team members F. Trail, M. Hausbeck, J. Del Castillo Múnera, C. Mukankusi, and J. Jacobs for isolates used in this study; D. McDuffee, J. MacCready, K. Porter, and C. Chen for their helpful discussions and technical assistance; and X. Liu and Q. Peng for their kind patience and agreement to collaborate.

\section{LITERATURE CITED}

Beakes, G. W., Glockling, S. L., and Sekimoto, S. 2012. The evolutionary phylogeny of the oomycete "fungi". Protoplasma 249:3-19.

Bilodeau, G. J., Lévesque, C. A., De Cock, A. W. A. M., Duchaine, C., Brière, S., Uribe, P., Martin, F. N., and Hamelin, R. C. 2007. Molecular detection of Phytophthora ramorum by real-time polymerase chain reaction using TaqMan, SYBR Green, and molecular beacons. Phytopathology 97: 632-642.

Borisy, G. G., and Taylor, E. W. 1967. The mechanism of action of colchicine. J. Cell Biol. 34:525-533.

Bradley, C. A. 2008. Effect of fungicide seed treatments on stand establishment, seedling disease, and yield of soybean in North Dakota. Plant Dis. 92: 120-125.

Brent, K. J., and Hollomon, D. W. 1998. Fungicide Resistance: The Assessment of Risk. FRAC Monogr. No. 2. Fungicide Resistance Action Committee, CropLife International, Brussels, Belgium.

Broders, K. D., Lipps, P. E., Paul, P. A., and Dorrance, A. E. 2007. Characterization of Pythium spp. associated with corn and soybean seed and seedling disease in Ohio. Plant Dis. 91:727-735.

Broders, K. D., Wallhead, M. W., Austin, G. D., Lipps, P. E., Paul, P. A., Mullen, R. W., and Dorrance, A. E. 2009. Association of soil chemical and physical properties with Pythium species diversity, community composition, and disease incidence. Phytopathology 99:957-967.

Cai, M., Miao, J., Song, X., Lin, D., Bi, Y., Chen, L., Liu, X., and Tyler, B. M. 2016. C239S mutation in the $\beta$-tubulin of Phytophthora sojae confers resistance to zoxamide. Front. Microbiol. 7:762.

Chen, W., and Van Vleet, S. M. 2016. Chickpea damping-off due to metalaxylresistant Pythium: An emerging disease in the Palouse. Washington State University Extension FS211E. https://research.wsulibs.wsu.edu:8443/xmlui/ handle/2376/6273

Chiappori, F., Pucciarelli, S., Merelli, I., Ballarini, P., Miceli, C., and Milanesi, L. 2012. Structural thermal adaptation of $\beta$-tubulins from the Antarctic psychrophilic protozoan Euplotes focardii. Proteins 80:1154-1166.

Del Castillo Múnera, J., and Hausbeck, M. K. 2016. Characterization of Pythium species associated with greenhouse floriculture crops in Michigan. Plant Dis. 100:569-576.

Dorrance, A. E., Berry, S. A., Bowen, P., and Lipps, P. E. 2004. Characterization of Pythium spp. from three Ohio fields for pathogenicity on corn and soybean and metalaxyl sensitivity. Plant Health Prog. 5. doi:10.1094/PHP2004-0202-01-RS

Dorrance, A. E., Ellis, M. L., McDuffee, D., and Arthur, K. 2012. Efficacy of ethaboxam toward species of Phytophthora and Pythium. (Abstr.) Phytopathology 102:S4.31.

Edgar, R. C. 2004. MUSCLE: Multiple sequence alignment with high accuracy and high throughput. Nucleic Acids Res. 32:1792-1797.

Ellis, M. L., Paul, P. A., Dorrance, A. E., and Broders, K. D. 2012. Two new species of Pythium, P. schmitthenneri and P. selbyi pathogens of corn and soybean in Ohio. Mycologia 104:477-487.

Fry, W. 2008. Phytophthora infestans: The plant (and $R$ gene) destroyer. Mol. Plant Pathol. 9:385-402.

Gilbert, G. S. 2002. Evolutionary ecology of plant diseases in natural ecosystems. Annu. Rev. Phytopathol. 40:13-43.
Gisi, U., and Sierotzki, H. 2015. Oomycete fungicides: Phenylamides, quinone outside inhibitors, and carboxylic acid amides. Pages 145-174 in: Fungicide Resistance in Plant Pathogens. H. Ishii and D. W. Hollomon, eds. Springer, New York.

Govers, F. 2001. Misclassification of pest as 'fungus' puts vital research on wrong track. Nature 411:633.

Hyde, K. D., Nilsson, R. H., Alias, S. A., Ariyawansa, H. A., Blair, J. E., Cai, L., CockA. W. A. M., de Dissanayake, A. J., Glockling, S. L., Goonasekara, I. D., Gorczak, M., Hahn, M., Jayawardena, R. S., KanJ. A. L., van Laurence, M. H., Lévesque, C. A., Li, X., Liu, J.-K., Maharachchikumbura, S. S. N., Manamgoda, D. S., Martin, F. N., McKenzie, E. H. C., McTaggart, A. R., Mortimer, P. E., Nair, P. V. R., Pawłowska, J., Rintoul, T. L., Shivas, R. G., Spies, C. F. J., Summerell, B. A., Taylor, P. W. J., Terhem, R. B., Udayanga, D., Vaghefi, N., Walther, G., Wilk, M., Wrzosek, M., Xu, J.-C., Yan, J., and Zhou, N. 2014. One stop shop: Backbones trees for important phytopathogenic genera: I. Fungal Divers. 67:21-125.

Jeffers, S. N. 1986. Comparison of two media selective for Phytophthora and Pythium species. Plant Dis. 70:1038-1043.

Jordan, M. A., and Wilson, L. 2004. Microtubules as a target for anticancer drugs. Nat. Rev. Cancer 4:253-265.

Katoh, K., and Standley, D. M. 2013. MAFFT multiple sequence alignment software version 7: Improvements in performance and usability. Mol. Biol. Evol. 30:772-780.

Kim, D. S., Chun, S. J., Jeon, J. J., Lee, S. W., and Joe, G. H. 2004. Synthesis and fungicidal activity of ethaboxam against Oomycetes. Pest Manage. Sci. 60:1007-1012.

Kim, D. S., Park, H. C., Chun, S. J., Yu, S. H., Choi, K. J., Oh, J. H., Shin, K. H., Koh, Y. J., Kim, B. S., Hahm, Y. I., and Chung, B. K. 1999. Field performance of a new fungicide ethaboxam against cucumber downy mildew, potato late blight and pepper Phytophthora blight in Korea. Plant Pathol. J. 15:48-52.

Lamberth, C., Kempf, H.-J., and Križ, M. 2007. Synthesis and fungicidal activity of N-2-(3-methoxy-4-propargyloxy) phenethyl amides. Part 3: Stretched and heterocyclic mandelamide oomyceticides. Pest Manage. Sci. 63:57-62.

Larkin, R. P. 2015. Soil health paradigms and implications for disease management. Annu. Rev. Phytopathol. 53:199-221.

Letunic, I., and Bork, P. 2016. Interactive Tree of Life (iTOL) v3: An online tool for the display and annotation of phylogenetic and other trees. Nucleic Acids Res. 44:W242-W245.

LéVesque, C. A., and De Cock, W. A. M. 2004. Molecular phylogeny and taxonomy of the genus Pythium. Mycol. Res. 108:1363-1383.

Lookabaugh, E. C., Ivors, K. L., and Shew, B. B. 2015. Mefenoxam sensitivity, aggressiveness, and identification of Pythium species causing root rot on floriculture crops in North Carolina. Plant Dis. 99:1550-1558.

Loper, J. E., Henkels, M. D., Shaffer, B. T., Valeriote, F. A., and Gross, H. 2008. Isolation and identification of rhizoxin analogs from Pseudomonas fluorescens Pf-5 by using a genomic mining strategy. Appl. Environ. Microbiol. 74:3085-3093.

Lu, Y., Chen, M. X., Li, W., and Miller, D. D. 2012. An overview of tubulin inhibitors that interact with the colchicine binding site. Pharmacol. Res. 29: 2943-2971.

Ma, Z., and Michailides, T. J. 2005. Advances in understanding molecular mechanisms of fungicide resistance and molecular detection of resistant genotypes in phytopathogenic fungi. Crop Prot. 24:853-863.

Matthiesen, R. L., Ahmad, A. A., and Robertson, A. E. 2016. Temperature affects aggressiveness and fungicide sensitivity of four Pythium spp. that cause soybean and corn damping off in Iowa. Plant Dis. 100:583-591.

Moorman, G. W., and Kim, S. H. 2004. Species of Pythium from greenhouses in Pennsylvania exhibit resistance to propamocarb and mefenoxam. Plant Dis. 88:630-632.

Mu, J. H., Bollon, A. P., and Sidhu, R. S. 1999. Analysis of $\beta$-tubulin cDNAs from taxol-resistant Pestalotiopsis microspora and taxol-sensitive Pythium ultimum and comparison of the taxol-binding properties of their products. Mol. Gen. Genet. 262:857-868.

Noel, Z. A., Rojas, A. J., Jacobs, J. L., and Chilvers, M. I. 2019. A highthroughput microtiter-based fungicide sensitivity assay for oomycetes using Z'-factor statistic. Phytopathology 109:1628-1637.

Noel, Z. A., Wang, J., and Chilvers, M. I. 2018. Significant influence of $\mathrm{EC}_{50}$ estimation by model choice and $\mathrm{EC}_{50}$ type. Plant Dis. 102:708-714.

Partida-Martinez, L. P., and Hertweck, C. 2005. Pathogenic fungus harbours endosymbiotic bacteria for toxin production. Nature 437:884-888.

Paul, B. 1992. Pythium radiosum: A new species with ornamented oogonia from France. Mycol. Helv. 5:1-8.

Paul, B. 1999. Pythium ornacarpum: A new species with ornamented oogonia isolated from soil in France. FEMS Microbiol. Lett. 180:337-344.

Price, M. N., Dehal, P. S., and Arkin, A. P. 2010. FastTree 2-Approximately maximum-likelihood trees for large alignments. PLoS One 5:e9490. 
Radmer, L., Anderson, G., Malvick, D., Rendahl, A., Mallik, A., and Kurle, J. E. 2016. Pythium, Phytophthora, and Phytopythium spp. associated with soybean in Minnesota, their relative aggressiveness to soybean and corn, and their sensitivity to seed treatment fungicides. Plant Dis. 101:62-67.

Raffaele, S., and Kamoun, S. 2012. Genome evolution in filamentous plant pathogens: Why bigger can be better. Nat. Rev. Microbiol. 10:417-430.

Raid, R. N., Raid, S., and Hartman, D. 2013a. Evaluation of fungicides for control of downy mildew on mustard greens. Plant Dis. Manage. Rep. 7: V025. https://www.plantmanagementnetwork.org/pub/trial/PDMR/volume7/ abstracts/V025.asp

Raid, R. N., Raid, S., and Hartman, D. 2013b. Evaluation of fungicides for control of downy mildew on sweet basil. Plant Dis. Manage. Rep. 7:V146. https://www.plantmanagementnetwork.org/pub/trial/PDMR/volume7/abstracts/ V146.asp

R Core Team. 2018. R: A Language and Environment for Statistical Computing. R Foundation for Statistical Computing, Vienna, Austria. https:// www.R-project.org/

Ritz, C., Baty, F., Streibig, J. C., and Gerhard, D. 2015. Dose-response analysis using R. PLoS One 10:e0146021.

Rojas, J. A., Jacobs, J. L., Napieralski, S., Bradley, C. A., Chase, T., Esker, P. D., Giesler, L., Jardine, D., Nelson, B. D., Malvick, D., Markell, S., Robertson, A. E., Rupe, J. C., Sweets, L., Wise, K., and Chilvers, M. I. 2017a. Oomycete species associated with soybean seedlings in North America-Part I: Identification and pathogenicity characterization. Phytopathology 107:280-292.

Rojas, J. A., Jacobs, J. L., Napieralski, S., Bradley, C. A., Chase, T., Esker, P. D., Giesler, L., Jardine, D., Nelson, B. D., Malvick, D., Markell, S., Robertson, A. E., Rupe, J. C., Sweets, L., Wise, K., and Chilvers, M. I. 2017b. Oomycete species associated with soybean seedlings in North America-Part II: Diversity and ecology in relation to environmental and edaphic factors. Phytopathology 107:293-304.

Ronquist, F., Teslenko, M., Van Der Mark, P., Ayres, D. L., Darling, A., Höhna, S., Larget, B., Liu, L., Suchard, M. A., and Huelsenbeck, J. P. 2012. MrBayes 3.2: Efficient Bayesian phylogenetic inference and model choice across a large model space. Syst. Biol. 61:539-542.

Rupe, J. C., Rothrock, C. S., Bates, G., Rosso, M. L., Avanzato, M. V., and Chen, P. 2011. Resistance to Pythium seedling disease in soybean. Pages 261-276 in: Soybean-Molecular Aspects of Breeding. A. Sudaric, ed. Intech, Rjeka, Croatia.

Schmitt, I., Partida-Martinez, L. P., Winkler, R., Voigt, K., Einax, E., Dölz, F., Telle, S., Wöstemeyer, J., and Hertweck, C. 2008. Evolution of host resistance in a toxin-producing bacterial-fungal alliance. ISME J. 2:632-641.
Shan, B., Medina, J. C., Santha, E., Frankmoelle, W. P., Chou, T., Learned, R. M., Narbut, M. R., Stott, D. S., Wu, P., Jaen, J. C., Rosen, T., Timmermans, P. B. M. W. M., and Beckmann, H. 1999. Selective, covalent modification of $\beta$-tubulin residue Cys-239 by T138067, an antitumor agent with in vivo efficacy against multidrug-resistant tumors. Proc. Natl. Acad. Sci. U.S.A. 96:5686-5691.

Swofford, D. L. 2002. PAUP*. Phylogenetic Analysis Using Parsimony (*and Other Methods), Version 4. Sinauer Associates, Sunderland, MA, U.S.A.

Thines, M. 2014. Phylogeny and evolution of plant pathogenic oomycetes-a global overview. Eur. J. Plant Pathol. 138:431-447.

Thines, M., and Kamoun, S. 2010. Oomycete-plant coevolution: Recent advances and future prospects. Curr. Opin. Plant Biol. 13:427-433.

Uchida, M., Roberson, R. W., Chun, S. J., and Kim, D. S. 2005. In vivo effects of the fungicide ethaboxam on microtubule integrity in Phytophthora infestans. Pest Manage. Sci. 61:787-792.

Uppuluri, S., Knipling, L., Sackett, D. L., and Wolff, J. 1993. Localization of the colchicine-binding site of tubulin. Proc. Natl. Acad. Sci. U.S.A. 90: 11598-11602.

Villa, N. O., Kageyama, K., Asano, T., and Suga, H. 2006. Phylogenetic relationships of Pythium and Phytophthora species based on ITS rDNA, cytochrome oxidase II and $\beta$-tubulin gene sequences. Mycologia 98: 410-422.

Vossenkemper, J. P., Nafziger, E. D., Wessel, J. R., Maughan, M. W., Rupert, M. E., and Schmidt, J. P. 2015. Early planting, full-season cultivars, and seed treatments maximize soybean potential. Crop. Forage Turfgrass Manage. 1:2015-0166.

Weiland, J. E., Santamaria, L., and Grünwald, N. J. 2014. Sensitivity of Pythium irregulare, P. sylvaticum, and P. ultimum from forest nurseries to mefenoxam and fosetyl-Al, and control of Pythium damping-off. Plant Dis. 98:937-942.

Whitham, S. A., Qi, M., Innes, R. W., Ma, W., Lopes-Caitar, V., and Hewezi, T. 2016. Molecular soybean-pathogen interactions. Annu. Rev. Phytopathol. 54:443-468.

Young, D. H. 2015. Anti-tubulin agents. Pages 93-103 in: Fungicide Resistance in Plant Pathogens. H. Ishii and D. W. Hollomon, eds. Springer, New York.

Young, D. H., Rubio, F. M., and Danis, P. O. 2006. A radioligand binding assay for antitubulin activity in tumor cells. J. Biomol. Screen. 11:82-89.

Young, D. H., and Slawecki, R. A. 2001. Mode of action of zoxamide (RH7281), a new oomycete fungicide. Pestic. Biochem. Physiol. 69:100-111.

Zitnick-Anderson, K. K., and Nelson, B. D. 2015. Identification and pathogenicity of Pythium on soybean in North Dakota. Plant Dis. 99:31-38. 